Johnson \& Wales University

ScholarsArchive@JWU

Health \& Wellness Department Faculty

Publications and Research

2017

\title{
Alcohol marketing in the Americas and Spain during the 2014 FIFA World Cup Tournament
}

Jonathan K. Noel

Thomas F. Babor

Katherine Robaina

Melissa Feulner

Alan Vendrame

See next page for additional authors

Follow this and additional works at: https://scholarsarchive.jwu.edu/health_fac

Part of the Medicine and Health Sciences Commons 
Authors

Jonathan K. Noel, Thomas F. Babor, Katherine Robaina, Melissa Feulner, Alan Vendrame, and Maristela Monteiro 


\title{
Alcohol marketing in the Americas and Spain during the 2014 FIFA World Cup Tournament
}

\author{
Jonathan K. Noel', Thomas F. Babor', Katherine Robaina', Melissa Feulner', Alan Vendrame² \& \\ Maristela Monteiro ${ }^{3}$
}

Department of Community Medicine and Health Care, University of Connecticut School of Medicine, Farmington, CT, USA,' Department of Psychiatry, Federal University of São Paulo, São Paulo, Brazil ${ }^{2}$ and Alcohol and Substance Abuse, Pan American Health Organization, Washington, DC, USA ${ }^{3}$

\section{ABSTRACT}

Background and aims To identify the nature of visual alcohol references in alcohol advertisements during televised broadcasts of the 2014 FIFA World Cup Tournament matches and to evaluate cross-national differences according to alcohol marketing policy restrictiveness. Design Content analysis using the Delphi method and identification of in-game sponsorships. Setting Television broadcasts of the 2014 FIFA World Cup in Argentina, Brazil, Canada, Finland, France, Mexico, Spain and the United States. Cases Eighty-seven alcohol advertisements; 20 matches. Measurements Quantitative rating scales, combined with the Delphi rating technique, were used to determine compliance of the alcohol advertisements with the International Alliance for Responsible Drinking's (IARD) Guiding Principles. Recordings of five matches from four countries were also used to identify the number of in- and out-of-game alcohol brand appearances. Findings A total of $86.2 \%$ of all unique alcohol advertisements contained at least one violation of IARD's Guiding Principles, with violation rates ranging from $72.7 \%$ (Mexico) to $100 \%$ (Brazil). Countries with the least restrictive marketing policies had a higher prevalence of violations in guidelines designed to protect minors. There were 2.76 in-game alcohol brand appearances and 0.83 out-of-game alcohol brand appearances per minute. Brand appearances did not differ across countries or according to a country's marketing policy restrictiveness. Conclusions Self-regulation and statutory policies were ineffective at limiting alcohol advertising during the 2014 FIFA World Cup Tournament television broadcasts. Most advertisements contained content that violated the self-regulation codes, and there were high levels of withinbroadcast brand appearances.

Keywords Advertising, alcohol, content, exposure, marketing, self-regulation.

Correspondence to: Thomas F. Babor PhD, MPH, Department of Community Medicine and Health Care, UConn School of Medicine, 263 Farmington Avenue, MC 6325, Farmington, CT, USA, 06030-6325. E-mail: babor@uchc.edu

Submitted 17 February 2016; initial review completed 29 February 2016; final version accepted 10 June 2016

\section{INTRODUCTION}

Alcohol advertising has been identified as a contributory cause to youth alcohol initiation and increased alcohol consumption [1,2]. In response, United Nations (UN) Member States have implemented national-level marketing policies ranging from statutory bans to industry self-regulation [3]. In contrast to government controls, self-regulation is a system whereby the alcohol industry assumes a dominant role in the development, implementation and enforcement of the policy. These voluntary codes of practice are created typically by alcohol producers, trade associations, national advertising organizations and other bodies sponsored by the alcohol industry. These 'codes' contain similar themes and have been summarized in the Alliance for Responsible Drinking's (IARD) Guiding Principles: Self-Regulation of Marketing Communications for Beverage Alcohol (Guiding Principles), an industry-sponsored initiative [4]. Additionally, some countries employ a coregulatory process in which government agencies provide oversight to industry self-regulation.

The Guiding Principles focus on alcohol advertisement content and exposure. The content guidelines contain five themes: responsible marketing communications, responsible alcohol consumption, health and safety, protection of minors and the effects of alcohol [4]. The exposure guidelines state that no alcohol advertisements should be broadcast or displayed where more than $30 \%$ of the audience is younger than the legal alcohol purchase age. 
Increasingly, alcohol marketing self-regulation has been criticized for the inability to limit content that promotes hazardous drinking. In the United States, an evaluation of all unique beer advertisements broadcast during the 1999-2008 National Collegiate Athletic Association's basketball tournaments demonstrated that $35-74 \%$ of all beer advertisements contained one or more violations of the US Beer Institute's marketing code, depending on the code version and scoring algorithm used [5]. After industry modifications in 2006, code violations were reduced significantly because previously unacceptable content, such as portrayals of illegal activity, was now permitted [5-8]. In Brazil, five advertisements that were rated by teenagers to be highly appealing all contained one or more violations of the local code [9], and similar results have been found for Australian television and magazine advertisements [10-13]. Among all published studies, guidelines prohibiting content that targets children, associating alcohol with success and promoting excessive alcohol consumption are consistently violated [14].

There has also been a proliferation of alcohol branding, particularly during sports programming. In the United States from 2000 to 2002, there were 7.7 minutes of alcohol advertisements per sporting event and 2.6 minutes of advertisements per college sporting event [15]. In the United Kingdom there were 1579 unique brand appearances in 420 hours of television reviewed, and nearly $60 \%$ occurred during sports programming [16]. During the EURO2012 football tournament, there were 1.24 alcohol references per minute of broadcast [17].

Previously, studies of the alcohol industry's voluntary codes of practice have been conducted in only a few developed countries. Moreover, no study has investigated intercountry differences in alcohol advertisement content or alcohol brand appearances within programs. The present study evaluates alcohol advertisements and other marketing activities recorded in eight countries during the 2014 FIFA World Cup Tournament. The aim was to evaluate compliance of advertisement content with an international marketing code proposed by the alcohol industry and to estimate the number of alcohol brand appearances within matches. We hypothesized that countries with greater marketing restrictions would have fewer code violations and less intragame alcohol branding.

\section{METHODS}

\section{Sample}

The FIFA World Cup Tournament was selected because it was expected to be one of the largest sporting events in history. The tournament was televised in 214 countries, and 3.2 billion people were estimated to have watched at least 1 minute of a tournament match [18]. In addition, Budweiser was an official 2014 World Cup sponsor [19].

Researchers in the following eight countries were recruited to record country-specific broadcasts of at least the last 16 matches of the 2014 FIFA World Cup Tournament. Countries were selected to represent a variety of alcohol marketing controls in the Region of the Americas and other relevant regions (e.g. Europe) of interest to the funder and based on the availability of resources and technological capabilities to conduct the study.

- Argentina: alcohol marketing in Argentina is selfregulated and must conform to a Code of Ethics drafted by the Chamber of Industries of Foods Products and enforced by the Council for Self-Regulating Advertising of Argentina [20].

- Brazil: the National Council of Advertising Self-Policy (Conselho Nacional de Auto Regulamentação Publicitária) enforces a self-regulated marketing code for beer products; beverages of higher alcohol content (i.e. distilled spirits, wine) are restricted by federal legislation [21].

- Canada: alcohol marketing is regulated by the Code for Broadcast Advertising of Alcoholic Beverages, which was promulgated by the Canadian Radio-Television and Telecommunications Commission, and is supported by a voluntary pre-clearance mechanism maintained by the alcohol producers [22].

- Finland: television alcohol advertisements are banned between 7 a.m. and 9 p.m. Television advertisements for products with greater than $1.2 \%$ alcohol by volume are also banned. The content of allowable advertising is strictly controlled [23].

- France: the Loi Evin prohibits television advertisements for products with greater than $2 \%$ alcohol. Advertising for products with less than $2 \%$ alcohol is allowed but restricted to the name of the producer, the product brand name and product characteristics [24].

- Mexico: alcohol marketing is limited by the General Law of Health and the Federal Radio and Television Law, which restrict when alcohol advertisements can be broadcast and the type of content they can contain [25].

- Spain: alcohol marketing is regulated by a federal law that prohibits advertisements from targeting minors, encouraging excessive consumption, or associating alcohol consumption with success, positive health effects or resolution of conflicts [26].

- United States: beer, wine and distilled spirits marketing are each governed by unique self-regulatory codes that contain guidelines on the content and placement of advertisements, although the codes have significant overlap [27-29]. 


\section{Policy restrictiveness}

Marketing policy restrictiveness was assessed using 2012 data from the World Health Organization's (WHO) Global Health Observatory database. Information on advertising restrictions for beer, wine and distilled spirits in 10 different media was abstracted and scored based on the criteria developed by Esser \& Jernigan [30]. Self-regulation/voluntary restrictions or no restrictions, partial restrictions and total bans were coded as 0,1 and 2, respectively. Countries were then categorized into one of five groups based on the total number of accumulated points. Countries were classified as least restrictive (0 points), slightly restrictive (1-15 points), restrictive (16-30 points), very restrictive (31-45 points) or most restrictive (46-60 points).

\section{Advertisement recording and processing}

Collaborating investigators in each country were instructed to record each match, the half-time show and at least 30 minutes of the pre- and post-game shows, respectively. Once complete, recordings were transferred to the University of Connecticut School of Medicine for processing via a cloud storage service. Full match recordings were available from all countries except Argentina, which only provided alcohol advertisements. All unique alcohol advertisements were identified from each country, abstracted into individual video files and stored on a cloud storage network.

\section{Advertisement rating procedure}

Because of between-country variation in alcohol marketing policies and national marketing codes, IARD's Guiding Principles were chosen as the standard code to compare all advertisements. The Guiding Principles are intended to apply to all alcoholic beverages and to all media. In addition, they have been endorsed by all major transnational alcohol producers [4].

Three language-specific panels (English, Spanish and Portuguese) were created to evaluate the advertisements. The English panel $(n=14)$ comprised eight American raters and six Canadian raters who viewed advertisements from Canada and the United States (English-language advertisements only). The Spanish panel $(n=14)$ comprised two American raters, four Argentinian raters, five Mexican raters, two Spanish raters and one Uruguayan rater who viewed advertisements from Argentina, Mexico, Spain and the United States (Spanish-language advertisements only). The Portuguese panel $(n=12)$ comprised 12 Brazilian raters who viewed advertisements from Brazil. In this context, the word 'expert' refers to individuals who have professional training or other experience with substance use disorders, alcohol marketing or public health, or who have expertise in protecting vulnerable populations. Experts rated each advertisement using a web-based rating questionnaire that was used in previous research [6]. The questionnaire was designed originally to evaluate the content guidelines of the US Beer Institute Code [8] and was subsequently modified slightly to cover the content guidelines in the Guiding Principles.

Three types of questions and response formats were used in the questionnaire. Five-point Likert scales measured the viewers' agreement or disagreement with statements of fact and opinion (e.g. 'This advertisement portrays abstinence or moderate consumption in a negative way'). These items were rated using the following response categories: strongly disagree, disagree, neither disagree nor agree, agree and strongly agree. A second type of measurement utilized age perception items, designed to measure the viewer's perception of the actor's age (e.g. 'How old do you think this actor is?'). A third measurement was designed to assess the viewer's perception of the amount of drinking taking place (e.g. 'How many drinks do you estimate this person is likely to consume in the situation shown in the advertisement?').

Advertisements were rated using a modified Delphi technique, a procedure designed to build group consensus around policy-relevant decisions that have no clear objective referent $[31,32]$. This procedure has been used previously to rate alcohol advertisements $[5,8]$. It utilized two successive ratings. During round 1 , all advertisements were rated independently by each rater. During round 2, all advertisements were rated again, but each rater was given their panel-specific mean rating from round 1 , the frequency of each response for Likert scale items, the range of responses for continuous items and comments (if any) provided by other panel members. Participants began the second rating session approximately 1 month after round 1 was completed. Participants were compensated with a $\$ 100$ gift card for completing both rounds of ratings. Good-to-excellent item-level inter-rater reliability was observed for the English [intraclass correlation coefficients $($ ICCs $)=0.52-0.98]$, Spanish $($ ICC $=0.58-0.97)$ and Portuguese (ICCs $=0.45-0.92$ ) panels. The brand, alcohol producer and type of beverage (beer, wine, distilled spirits or hard cider) were recorded by study staff for each included advertisement.

Code violations were calculated using a previously defined scoring algorithm [5]. Briefly, individual ratings were first dichotomized to indicate the status of an item-specific violation. Then, a sub-guideline violation was indicated if any item-specific violations that pertain to a sub-guideline were recorded. A guideline violation existed if one or more sub-guidelines that pertain to a guideline existed. An advertisement was coded as containing a violation when $50 \%$ or more of the raters indicated that a guideline violation existed. 


\section{Alcohol brand appearances}

The frequency of alcohol brand logos was assessed in five matches broadcast in four countries (i.e. Brazil, Canada, Mexico and the United States, $n=20$ ). Countries and matches were selected based on the quality of the match recording. Brand logos appearing during the recordings were assessed using methodology applied previously to European Football Championship matches, which included identifying each unique brand logo occurrence, identifying where the logo occurred during the broadcast (i.e. pitch-side; interview boards; within the pre-, half- or post- game show; on-screen scoreboard, fans or other) and when the brand logo appeared (i.e. pre-match, first half, half-time, second half, pre-extra time 1, extra time 1 , time between extra time 1 and 2, extra time 2, prepenalty kicks, penalty kicks or post-match) $[17,33]$. This procedure was performed by two graduate students at the University of Connecticut School of Medicine. There was excellent inter-rater reliability $($ ICC $=0.953)$. The mean number of brand appearances detected by the raters was used for the analysis.

\section{Statistical analysis}

Differences in overall guideline and sub-guideline violation rates by policy restrictiveness category, alcohol producer and beverage type were assessed using the FreemanHalton extension of Fisher's exact test. $\chi^{2}$ tests could not be performed due to low expected cell counts in many cells. The comparison between alcohol producers was performed between $\mathrm{AB}$ InBev, SABMiller, Heineken and all other producers. AB InBev, SABMiller and Heineken each created more than $15 \%$ of all unique advertisements broadcast. No other alcohol producer created more than $5 \%$ of unique advertisements broadcast. A comparison of beverage types was performed among beer, distilled spirits and all others. Wine and hard cider were combined due to low numbers of unique advertisements.

Differences in overall, in-game and out-of-game alcohol brand appearances per minute were assessed using the independent-samples Kruskal-Wallis test. Differences were assessed by country, alcohol policy restrictiveness and match. Brand appearances based on tournament round were not assessed due to an insufficient number of matches assessed. Statistical analysis was performed using IBM SPSS Statistics for Windows, version 21.0 (Armonk, NY, USA). Statistical significance was set at 0.05 a priori.

\section{RESULTS}

Overall, 87 unique advertisements were obtained. Eighty-four of these were for 39 unique alcohol brands produced by 20 alcohol companies (Supporting information,
Table S1). Three advertisements for alcohol beverage stores were also included in the sample. No advertisements were identified from Finland or France, and these countries were excluded from further analysis. Brands with the greatest number of advertisements in the sample were Tecate (eight advertisements), Budweiser (seven) and Corona (six). AB InBev (27), SABMiller (13) and Heineken (13) produced the most unique advertisements. The greatest number of advertisements were for beer (62 advertisements) and distilled spirits (13).

Overall, $86.2 \%$ of unique advertisements were found to contain at least one code violation (Table 1) and, on average, each advertisement contained 2.4 guideline violations and 4.7 sub-guideline violations. Guiding Principle 5 (the effects of alcohol, 85.1\%) and three (health and safety, $79.3 \%$ ) were each violated by the majority of unique advertisements broadcast. A majority of advertisements also presented alcohol as necessary for social success $(83.9 \%)$, as a stimulant, sedative or tranquilizer $(73.6 \%)$, as a means of removing social or sexual inhibitions $(67.8 \%)$ or as a method to enhance physical, sporting or mental ability (64.4\%). Moreover, $39.1 \%$ of advertisements portrayed excessive alcohol consumption, and $17.2 \%$ of advertisements used actors that appeared to be under the legal alcohol purchase age.

For policy restrictiveness the United States, consisting of both English and Spanish language advertisements, was categorized as least restrictive ( 0 points). Canada (12 points) was categorized as slightly restrictive and Argentina (24 points), Brazil (30 points), Mexico (24 points) and Spain (26 points) were categorized as restrictive. Finland (39 points) and France (36 points) were categorized as very restrictive. No differences were detected in the overall violation rate based on the restrictiveness of alcohol marketing policies (Table 2). However, advertisements from countries with slightly restrictive or restrictive marketing policies violated Guideline 1 (responsible marketing communications) more often than advertisements from countries with the least restrictive marketing policies $(P<0.001)$. Conversely, advertisements from countries with the least restrictive marketing policies violated Guideline 4 (minors) more often than advertisements from countries with slightly restrictive or restrictive marketing policies $(P=0.033)$.

There was no significant difference in the overall violation rate between alcohol producers $(P=0.090)$, although significant differences were detected in four of the five Guiding Principles guidelines (Table 3). It appears that Guideline 1 was violated most often by advertisements for Heineken brands $(P=0.027)$ and Guideline 4 was violated most often by advertisements for $\mathrm{AB}$ InBev and SABMiller brands $(P=0.007)$. Despite statistically significant differences in the violation rates of Guidelines $3(P=0.001)$ and $5(P=0.046)$, the majority of advertisements from 


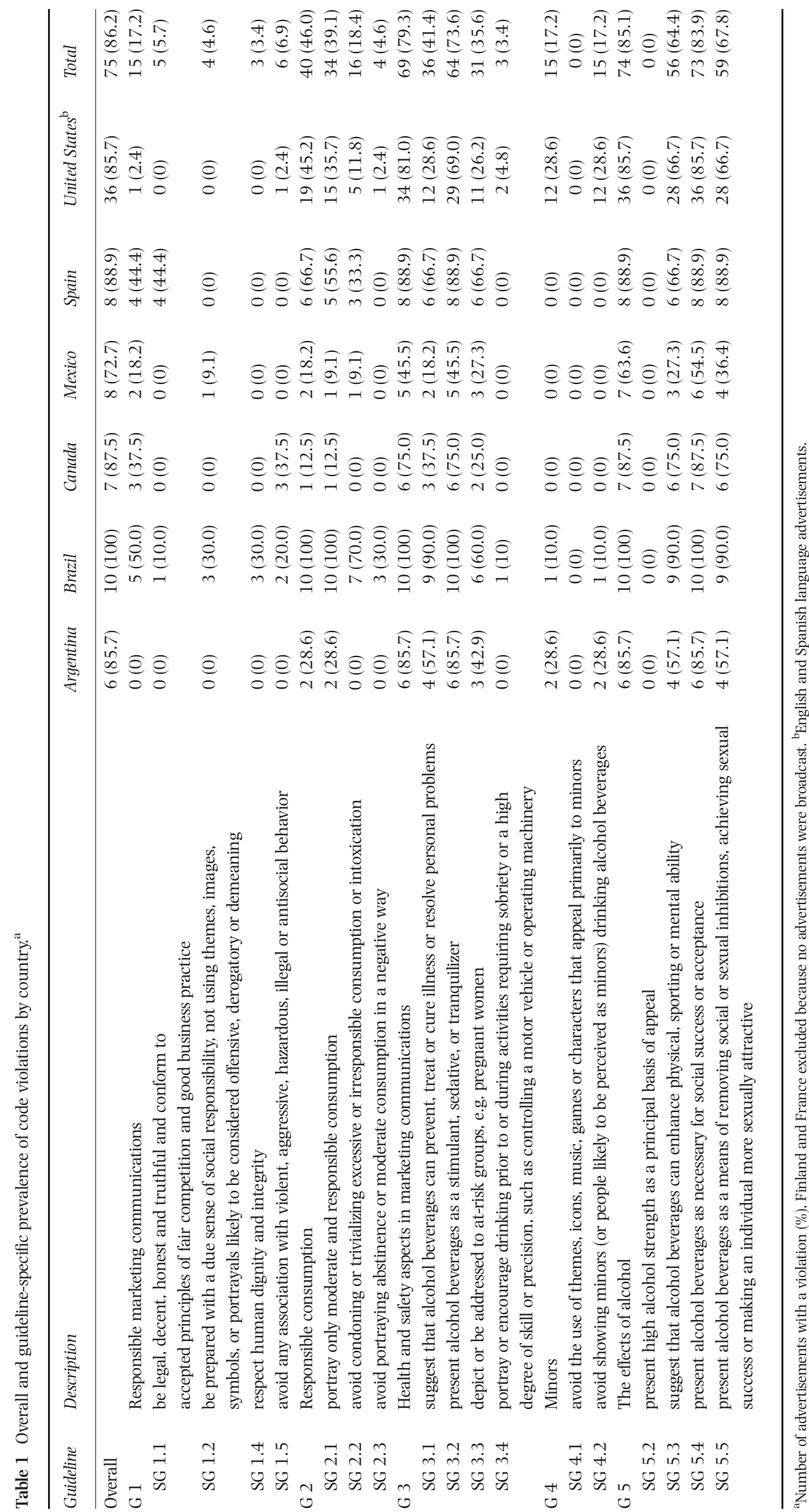


Table 2 Overall and guideline-specific prevalence of code violations by policy restrictiveness. ${ }^{\text {a }}$

\begin{tabular}{llllll}
\hline Guideline & Description & Least restrictive $(n=42)^{\mathrm{b}}$ & ${\text { Slightly restrictive }(n=8)^{\mathrm{c}}}$ & ${\text { Restrictive }(n=37)^{\mathrm{d}}}$ & $P$ \\
\hline Overall & & $36(85.7)$ & $7(87.5)$ & $32(86.5)$ & 1.00 \\
G 1 & Responsible marketing & $1(2.4)$ & $3(37.5)$ & $11(29.7)$ & $<0.001$ \\
G 2 & Responsible consumption & $19(45.2)$ & $1(12.5)$ & $20(54.1)$ & 0.107 \\
G 3 & Health and safety aspects & $34(81.0)$ & $6(75.0)$ & $29(78.4)$ & 0.862 \\
G 4 & Minors & $12(28.6)$ & $7(0)$ & $3(8.1)$ & 0.033 \\
G 5 & The effects of alcohol & $36(85.7)$ & $7(87.5)$ & $31(83.8)$ & 1.00 \\
\hline
\end{tabular}

${ }^{a}$ Number of advertisements with a violation (\%), very restrictive excluded because no advertisements were broadcast. ${ }^{b}$ US (English and Spanish language advertisements ); ${ }^{\mathrm{c}}$ Canada; ${ }^{\mathrm{d}}$ Argentina, Brazil, Mexico and Spain.

Table 3 Overall and guideline-specific prevalence of potential code violations by alcohol producer. ${ }^{\text {a }}$

\begin{tabular}{llcccrr}
\hline Guideline & Description & A-B InBev $(n=27)$ & SABMiller $(n=13)$ & Heineken $(n=13)$ & All others $(n=31)$ & $P$ \\
\hline Overall & & $27(100)$ & $11(84.6)$ & $11(84.6)$ & $26(83.9)$ & 0.090 \\
G 1 & Responsible marketing & $2(7.4)$ & $1(7.7)$ & $6(46.2)$ & $6(19.4)$ & 0.027 \\
G 2 & Responsible consumption & $17(63.0)$ & $5(38.5)$ & $4(30.8)$ & $14(45.2)$ & 0.213 \\
G 3 & Health and safety aspects & $27(100)$ & $10(76.9)$ & $7(53.8)$ & $25(80.6)$ & 0.001 \\
G 4 & Minors & $9(33.3)$ & $4(30.8)$ & $0(0)$ & $2(6.5)$ & 0.007 \\
G 5 & The effects of alcohol & $27(100)$ & $11(84.6)$ & $10(76.9)$ & $26(83.9)$ & 0.046 \\
\hline
\end{tabular}

${ }^{\mathrm{a}}$ Number of advertisements it appears contained a violation (\%).

all producers seem to have violated these guidelines (53.8-100\% for Guideline 3; 76.9-100\% for Guideline 5).

There was no significant difference in the overall violation rate based on beverage type $(P=0.142)$, although some significant differences were found at the guideline level (Table 4). Advertisements for beer brands violated Guideline $2(P=0.041)$ more often than advertisements for distilled spirits or other product types. More than $75 \%$ of the advertisements for each product type violated Guidelines 3 and 5.

Overall, there were 1.90 brand appearances per minute of broadcast (Table 5). There were 2.76 in-game brand appearances per minute overall, with broadcasts ranging from 2.58 (Brazil) to 2.93 (Canada) appearances per minute. There were 0.83 out-of-game brand appearances overall, with broadcasts ranging from 0.57 (United States) to 1.08 (Canada) brand appearances per minute. The majority of brand appearances $(88 \%)$ came from pitchside, with fans $(7 \%)$ a distant second. Significant differences between countries were detected in the number of brand appearances in the following areas: overall on-screen $(P=0.010)$, in-game on-screen $(P<0.001)$, out-of-game on-screen $(P=0.022)$, out-of-game pitch-side $(P=0.046)$ and interview boards $(P=0.009)$.

There were no significant differences in overall alcohol brand appearances when classifying countries by alcohol marketing policy restrictiveness $(P=0.632$; Supporting information, Table S2). Countries with slightly restrictive policies had more on-screen brand appearances per minute compared to other countries $(P=0.016)$ and countries with restrictive policies had the most brand appearances per minute attributable to interview boards $(P=0.004)$.

There were several significant differences in brand appearances based on match (Supporting information,

Table 4 Overall and guideline-specific prevalence of code violations by beverage type. ${ }^{\text {a }}$

\begin{tabular}{|c|c|c|c|c|c|}
\hline Guideline & Description & $\operatorname{Beer}(n=62)$ & Distilled spirits $(n=13)$ & All others $(n=9)$ & $P$ \\
\hline Overall & & 57 (91.9) & $10(76.9)$ & $8(88.9)$ & 0.142 \\
\hline G 1 & Responsible marketing & $14(22.6)$ & $1(7.7)$ & $0(0)$ & 0.219 \\
\hline G 2 & Responsible consumption & $34(54.8)$ & $5(38.5)$ & $1(11.1)$ & 0.041 \\
\hline G 3 & Health and safety aspects & $51(82.3)$ & $10(76.9)$ & $8(88.9)$ & 0.801 \\
\hline G 4 & Minors & $13(21.0)$ & $0(0)$ & $2(22.2)$ & 0.169 \\
\hline G 5 & The effects of alcohol & $56(90.3)$ & $10(76.9)$ & $8(88.9)$ & 0.329 \\
\hline
\end{tabular}

${ }^{\mathrm{a}}$ Number of advertisements with a violation (\%). 
Table 5 Overall, in-game and out-of-game alcohol brand appearances by country. ${ }^{\text {a }}$

\begin{tabular}{|c|c|c|c|c|c|c|}
\hline Location & Total & Brazil & Canada & Mexico & United States & $P$-value \\
\hline \multicolumn{7}{|l|}{ Overall } \\
\hline Total & $1.90(0.54)$ & $1.70(0.41)$ & $2.14(0.77)$ & $1.92(0.51)$ & $1.86(0.49)$ & 0.765 \\
\hline Pitch-side & $1.68(0.53)$ & $1.40(0.44)$ & $1.96(0.70)$ & $1.65(0.49)$ & $1.70(0.46)$ & 0.336 \\
\hline Fans & $0.13(0.07)$ & $0.17(0.07)$ & $0.12(0.07)$ & $0.14(0.08)$ & $0.10(0.01)$ & 0.374 \\
\hline On-screen & $0.02(0.01)$ & $0.01(0.01)$ & $0.03(0.01)$ & $0.03(0.02)$ & $<0.01(<0.01)$ & 0.010 \\
\hline Other & $0.02(0.02)$ & $0.02(0.02)$ & $0.01(0.01)$ & $0.01(0.01)$ & $0.03(0.03)$ & 0.225 \\
\hline \multicolumn{7}{|l|}{ In-game } \\
\hline Total & $2.76(0.99)$ & $2.58(0.92)$ & $2.93(1.08)$ & $2.81(1.31)$ & $2.74(0.94)$ & 0.904 \\
\hline Pitch-side & $2.64(0.92)$ & $2.46(0.87)$ & $2.80(1.00)$ & $2.66(1.19)$ & $2.64(0.90)$ & 0.902 \\
\hline Fans & $0.12(0.08)$ & $0.11(0.05)$ & $0.11(0.09)$ & $0.14(0.12)$ & $0.10(0.05)$ & 0.821 \\
\hline On-screen & $<0.01(<0.01)$ & $0.00(0.00)$ & $0.02(<0.01)$ & $0.00(0.00)$ & $0.00(0.00)$ & $<0.001$ \\
\hline Other & $<0.01(<0.01)$ & $0.00(0.00)$ & $<0.01(<0.01)$ & $0.00(0.00)$ & $0.00(0.00)$ & 0.392 \\
\hline \multicolumn{7}{|l|}{ Out-of-game } \\
\hline Total & $0.83(0.35)$ & $0.81(0.28)$ & $0.88(0.25)$ & $1.08(0.43)$ & $0.57(0.30)$ & 0.162 \\
\hline Pitch-side & $0.52(0.26)$ & $0.38(0.17)$ & $0.66(0.21)$ & $0.69(0.28)$ & $0.33(0.17)$ & 0.046 \\
\hline Fans & $0.16(0.09)$ & $0.22(0.12)$ & $0.14(0.06)$ & $0.15(0.07)$ & $0.12(0.09)$ & 0.557 \\
\hline Interview boards ${ }^{c}$ & $0.09(0.13)$ & $0.15(0.08)$ & $0.02(0.05)$ & $0.16(0.21)$ & $0.01(0.02)$ & 0.009 \\
\hline On-screen & $0.03(0.03)$ & $0.02(0.02)$ & $0.04(0.01)$ & $0.05(0.03)$ & $<0.01(<0.01)$ & 0.022 \\
\hline Other & $0.05(0.06)$ & $0.04(0.04)$ & $0.02(0.03)$ & $0.02(0.03)$ & $0.11(0.08)$ & 0.129 \\
\hline Commercials ${ }^{\mathrm{b}, \mathrm{c}}$ & $3.65(3.21)$ & $5.70(2.39)$ & $3.20(1.48)$ & $4.20(5.02)$ & $1.50(2.06)$ & 0.155 \\
\hline
\end{tabular}

${ }^{a}$ Appearances per minute, mean (standard deviation); ${ }^{b}$ number per broadcast; ${ }^{c}$ only occurred out-of-game.

Table S3). The Argentina versus Belgium match had the greatest number of overall $(P=0.014)$, overall pitch-side $(P=0.019)$, total in-game $(P=0.001)$, in-game pitch-side $(P=0.001)$ and in-game fans $(P=0.023)$ brand appearances per minute. No significant differences were detected in out-of-game brand appearances ( $P$ s $=0.238-0.848)$.

\section{DISCUSSION}

Violations of IARD's Guiding Principles were highly prevalent in alcohol advertisements broadcast during the 2014 FIFA World Cup Tournament. These advertisements depicted alcohol as contributing to social success, sexual attractiveness and enhanced physical or mental ability, in addition to portraying excessive alcohol consumption. Although differences were noted among brands, there were no significant differences in the overall violation rate based on marketing policy restrictiveness among countries where alcohol advertising was broadcast. In contrast, two countries with highly restrictive legislative policies (Finland and France) were found to be free of all alcohol advertisements on commercial television stations used to broadcast the 2014 World Cup matches. Moreover, among the countries that provided recordings of sufficient quality, brand appearances per minute did not differ by policy restrictiveness. Taken together, these results indicate that self-regulatory structures, or partial statutory restrictions, on alcohol marketing content are ineffective in protecting young people and other vulnerable populations from exposure to potentially harmful alcohol marketing content.
In contrast, the qualitative findings from France and Finland suggest strict legislative policies against TV advertising can prevent exposure to this type of alcohol marketing.

The code violation rates reported here are higher than those reported in other research. Studies of television advertisements conducted in Australia and the United States have reported rates from 46.2 to $74 \%$ [5,11,13], although the results are consistent with the types of violations reported previously. There are several non-mutually exclusive explanations for the high code violation rate of the advertisements evaluated. High violation rates may indicate that the industry's promotion of marketing self-regulation is more of a lobbying or public perception tool than a concerted effort to restrict the content of alcohol advertising. For example, increases in Budweiser's market share in 2010 were attributed to its sponsorship of the 2010 FIFA World Cup Tournament [34], and Carlsberg estimated that each World Cup match results in 21 million additional pints of beer being sold in pubs across the United Kingdom [35]. Moreover, for several countries, the reported rates serve as a baseline violation rate that may not be comparable to previously published studies. Indeed, this is the first study to report code violation rates for every included country that broadcast alcohol advertising except the United States and the first to include alcohol advertising from non-high-income countries.

The consistent effort to portray alcohol as a psychoactive substance and associate alcohol with mental, physical, sexual and social success across country and policy 
restrictiveness categories may be a result of significant consolidation within the alcohol industry, which now consists of a small number of competing companies that market their products aggressively [36] These multi-national producers may be using similar strategies to position their products across countries and across cultures, while simultaneously disregarding local marketing policies.

In addition to the commercial messages, alcohol brand images were present consistently throughout the World Cup match broadcasts analyzed, primarily in the form of pitch-side images and fans' drinking from branded containers. Using data reported by Kantar Media, we estimate that approximately 325 million youth aged under 16 years and 850 million young adults 16-34 years watched at least 1 minute of the 2014 World Cup and were exposed to such images [37]. While a simple brand logo conforms to IARD's Guiding Principles, the contexts in which these logos are deliberately placed raise significant concerns. Pitch-side logos appearing during game play may be attempts to associate the advertised brands indirectly with physical or athletic success. This association may be in violation of the Guiding Principles' Sub-Guideline 5.3, which states that advertising 'should not suggest that alcohol can enhance physical or sporting ability' [4].

Displaying alcohol brand logos on branded drinking cups and clothing raises an additional concern. Because of the variability in the legal purchase age (LPA) across countries, it is plausible that an individual drinking from a branded cup is over the LPA in the country where the match is played (e.g. 18 years old in Brazil) but younger than the LPA in another country (e.g. 21 years old in the United States). Additionally, even if the individuals are over the LPA, it is plausible that they do not meet Guiding Principles' Sub-Guideline 4.2, which states that alcohol advertising 'should avoid showing minors or people likely to be perceived as minors' [4]. We are not implying that alcohol companies are responsible for the decisions of a broadcasting company, but they should be held accountable for creating an environment where possible violations of the Guiding Principles could occur.

\section{Limitations}

This study illustrates the challenges associated with implementing a public health surveillance system to monitor alcohol marketing in multiple countries simultaneously. Because system fidelity was not $100 \%$ and country-specific broadcasts were not selected randomly, the sample may not be representative of global alcohol advertising practices, and generalization to other regions may be limited. However, the sample covers countries differing in population, size and income. The advertisements also cover three major language groups (i.e. Spanish,
Portuguese and English). Intercountry differences or differences between restrictiveness categories may be confounded by cultural or socio-economic factors; however, country-specific advertisements were often rated by experts from other countries, which may diminish this effect. Unfortunately, differences in the content of alcohol advertisements could not be compared statistically across all policy restrictiveness categories because alcohol advertisements were absent from countries with the most restrictive policies (Finland and France).

The experts who evaluated the advertisements could be biased against the alcohol industry, thus overestimating the prevalence of violations, although we believe this to be unlikely. There were several sub-guidelines of the Guiding Principles with which all or nearly all advertisements were compliant, and a minority of advertisements violated catchall sub-guidelines, such as Sub-Guideline 3.3, which prohibits depicting or addressing at-risk groups [4]. Furthermore, results of the second round of advertisement ratings were more conservative than the preliminary ratings, indicating that the raters may have re-assessed their perceptions during the Delphi process. Low item-level inter-rater reliability was detected for a limited number of questions used during the Delphi rating process, although we believe this is unlikely to affect the results. Multiple questions are used to determine whether a single guideline or sub-guideline has been violated, and because a violation was defined based on agreement between raters, disagreement will result in underestimation of violation rates.

\section{CONCLUSIONS}

Within alcohol advertisements broadcast during the 2014 FIFA World Cup Tournament, it appears that violations of ICAP's Guiding Principles were highly prevalent, and there was a significant amount of brand appearances during the non-commercial section of match broadcasts. Common violations of the Guiding Principles included associations with success, promoting alcohol as a psychoactive substance, and displaying or promoting excessive alcohol consumption. In-game brand appearances may also violate the Guiding Principles by associating alcohol brands with athletic success and individuals under the LPA. In our opinion these results indicate that self-regulation and partial restrictions are ineffective at limiting alcohol marketing content and that stricter policies may be needed.

\section{Declaration of interests}

None.

\section{Acknowledgements}

This study was commissioned by the Pan American Health Organization (Contract no. SC-14-02239). The authors 
are grateful to the following individuals who assisted with the recording of the games, with the recruitment of the rating panels and translations of rating questions: Karina Conde, Mariana Cremonte, María Elena Medina-Mora, Juan Miguel Rey Pino, Tim Stockwell, Kara Thompson and Jorge A. Villatoro Velázquez. This is a one of a series of papers published in a Supplement to Addiction entitled: "The Regulation of Alcohol Marketing: From Research to Public Health Policy." This supplement was published with financial support from Alcohol Research UK and the Institute of Alcohol Studies. Preliminary versions of the majority of these manuscripts were first presented at a meeting organized by the Pan American Health Organization. [Correction: the preceding three sentences were added on 25 October 2016, after original online publication]

\section{References}

1. Anderson P., de Bruijn A., Angus K., Gordon R., Hastings G. Impact of alcohol advertising and media exposure on adolescent alcohol use: a systematic review of longitudinal studies. Alcohol Alcohol 2009; 44: 229-43.

2. Smith L. A., Foxcroft D. R. The effect of alcohol advertising, marketing and portrayal on drinking behaviour in young people: systematic review of prospective cohort studies. BMC Public Health 2009; 9.

3. World Health Organization (WHO). Global status report on and alcohol and health 2014. Geneva, Switzerland: WHO; 2014. Available at: http://apps.who.int/iris/ bitstream/10665/112736/1/9789240692763_eng.pdf?ua=1 (accessed 7 December 2015) (Archived at http://www. webcitation.org/6ieaKX0ei on 30 June 2016).

4. International Center for Alcohol Policies (ICAP). Guiding Principles: Self-Regulation of Marketing Communications for Beverage Alcohol. Washington DC, USA: ICAP; 2011. Available at: http://www.iard.org/wp-content/uploads/ 2016/01/Guiding-Principles.pdf (accessed 30 June 2016) (Archived at http://www.webcitation.org/6iU8ThuF on 23 June 2016)

5. Babor T. F., Xuan Z., Damon D., Noel J. An empirical evaluation of the US Beer Institute's self-regulation code governing the content of beer advertising. Am J Public Health 2013; 103: e45-51.

6. Babor T. F., Xuan Z., Proctor D. Reliability of a rating procedure to monitor industry self-policy codes governing alcohol advertising content. J Stud Alcohol Drugs 2008; 69: 235-42.

7. Babor T. F., Xuan Z., Damon D. Changes in the self-policy guidelines of the US Beer Code reduce the number of content violations reported in TV advertisements. J Public Affairs 2010; 10: 6-18.

8. Babor T. F., Xuan Z., Damon D. A new method for evaluating compliance with industry self-policy codes governing the content of alcohol advertising. Alcohol Clin Exp Res 2013; 37: 1787-93.

9. Vendrame A., Pinsky I. e Silva R. S., Babor T. Assessment of self-regulatory code violations in Brazilian television beer advertisements. J Stud Alcohol Drugs 2010; 71: 445-51.

10. Jones S. C., Hall D., Munro G. How effective is the revised regulatory code for alcohol advertising in Australia? Drug Alcohol Rev 2008; 27: 29-38.
11. Jones S. C., Phillipson L., Barrie L. 'Most men drink... especially like when they play sports'-alcohol advertising during sporting broadcasts and the potential impact on child audiences. J Public Affairs 2010; 10: 59-73.

12. Jones S. C., Donovan R. J. Self-policy of alcohol advertising: is it working for Australia? J Public Affairs 2002; 2: 153-65.

13. Donovan K., Donovan R., Howat P., Weller N. Magazine alcohol advertising compliance with the Australian Alcoholic Beverages Advertising Code. Drug Alcohol Rev 2007; 26: 73-81.

14. Noel J. K., Babor T. F., Robaina K. Industry Self-regulation of Alcohol Marketing: A Systematic Review of Content and Exposure Research. Addiction 2017; 112(Suppl. 1): $28-50$.

15. Zwarun L. Ten years and 1 master settlement agreement later: the nature and frequency of alcohol and tobacco promotion in televised sports, 2000 through 2002. Am J Public Health 2006; 96: 1492-7.

16. Lyons A., McNeill A., Britton J. Alcohol imagery on popularly viewed television in the UK. J Public Health (Oxf) 2014; 36: 426-34. Available at: http://jpubhealth.oxfordjournals.org/ content/early/2013/08/07/pubmed.fdt074.full.pdf+html (accessed 12 September 2015).

17. Adams J., Coleman J., White M. Alcohol marketing in televised international football: frequency analysis. BMC Public Health 2014; 14: 473.

18. KantarSport. 2010 FIFA World Cup South Africa Television Audience Report. London, UK: KantarSport; 2010. Available at: http://www.fifa.com/mm/document/affederation/tv/01/ 47/32/73/2010fifaworldcupsouthafricatvaudiencereport.pdf (accessed 22 May 2015) (Archived at http://www. webcitation.org/6ieabSDU3 on 30 June 2016).

19. Smith C. The biggest sponsors of Brazil's 2014 World Cup spend big to engage with fans. Forbes 12 June 2014. Available at: http://www.forbes.com/sites/chrissmith/2014/06/12/ the-biggest-sponsors-of-brazils-2014-world-cup/ (accessed 7 July 2015) (Archived at http://www.webcitation.org/ 6ieafghWW on 30 June 2016).

20. Consejo de Autorregulación Publicitaria. Código de Ética y Autorregulación Publicitaria. Buenos Aires, Argentina: Consejo de Autorregulación Publicitaria; 2007. Available at: http://www.conarp.org.ar/codigo.htm (accessed 12 October 2015) (Archived at http://www.webcitation.org/6ieavWZnu on 30 June 2016).

21. Conselho de Auto-Regulamentação Publicitária. Código brasileiro de auto-regulamentação Publicitária. São Paulo, Brazil: Conselho de Auto-Regulamentação Publicitária; 2014. Available at: http://www.conar.org.br (accessed 12 October 2015) (Archived at http://www.webcitation.org/ 6ieayjVwd on 30 June 2016).

22. Canadian Radio-Television and Telecommunications Commission. Code for broadcast advertising of alcoholic beverages. Ontario, Ottawa, Canada: Canadian RadioTelevision and Telecommunications Commission;1996. Available at: http://crtc.gc.ca/eng/television/publicit/ codesalco.htm (accessed 30 June 2016) (Archived at http:// www.webcitation.org/6ieb41wJT on 30 June 2016).

23. Laki alkoholilain 152/2014 33 ja 40 §:n muuttamisesta 1143/ 1994. Eduskunta Annettu Helsingissä 28 päivänä helmikuuta [Law on Alcohol Act 152/2014 § Amending 33 and 40 of the Alcohol Act 1143/1994. The Finnish Parliament in Helsinki. 28 February]. Available at: http://www.finlex.fi/fi/laki/alkup/ 2014/20140152 (accessed on 30 June 2016) (Archived at http://www.webcitation.org/6ieo3cblU on 30 June 2016). 
24. LOI relative à la lutte contre le tabagisme et l'alcoolisme 1991 Pub. L. No. 91-32 [Act concerning the fight against smoking and alcoholism 1991 Pub. L. No. 91-32]. Available at: https://www.legifrance.gouv.fr/affichTexte.do?cidTexte= JORFTEXT000000344577\&categorieLien=id (accessed 30 June 2016) (Archived at http://www.webcitation.org/ 6ieoHffQs on 30 June 2016).

25. Hurtado M. Advertising to children in Mexico. Young Consumers 2013; 14. Available at: http://www.emeraldinsight. com/doi/full/10.1108/yc.2013.32114aaa.002 (accessed 10 October 2015) (Archived at http://www.webcitation.org/ 6ieb9Fge4 on 30 June 2016).

26. Ley 25/1994, 12 Julio. incorporación del ordenamiento español de la directive 89/552/CEE modificación de la ley 22/1999, 7 Junio. Las Cortes Generales [Law 25/1994, July 12. Incorporation into the Spanish Law Directive 89/552/CEE amending law 22/1999, June 7. Parliament]. Available at: https://www.boe.es/buscar/doc.php?id=BOE-A-1999-12694 (accessed 30 June 2016) (Archived at http://www. webcitation.org/6iepmNe58 on 30 June 2016).

27. US Beer Institute. Beer Institute Advertising and Marketing Code. Washington, DC, USA: US Beer Institute; 2015 Available at: http://www.beerinstitute.org/assets/uploads/ general-upload/2015-Beer-Ad-Code-Brochure.pdf (accessed 12 October 2015) (Archived at http://www.webcitation. org/6iebC4XFa on 30 June 2016).

28. Distilled Spirits Council of the United States, Inc. Code of Responsible Practices for Beverage Alcohol Advertising and Marketing. Washington, DC, USA: Distilled Spirits Council of the United States, Inc.; 2011. Available at: http://www.discus.org/assets/1/7/May_26_2011_DISCUS_ Code_Word_Version1.pdf (accessed 12 October 2015) (Archived at http://www.webcitation.org/6iebG1P4r on 30 June 2016).

29. Wine Institute. Code of Advertising Standards. San Francisco, CA, USA: Wine Institute; 2011. Available at: http://www. wineinstitute.org/initiatives/issuesandpolicy/adcode/details (accessed 12 October 2015) (Archived at http://www. webcitation.org/ 6iebKfL8W on 30 June 2016).

30. Esser M., Jernigan D. Assessing restrictiveness of national alcohol marketing policies. Alcohol Alcohol 2014; 49: 557-62.
31. Hasson F., Keeney S., McKenna H. Research guidelines for the Delphi survey technique. J Adv Nurs 2000; 32: 1008-15.

32. Powell C. The Delphi technique: myths and realities. J Adv Nurs 2003; 41: 376-82.

33. Graham A., Adams J. Alcohol marketing in televised English professional football: a frequency analysis. Alcohol Alcohol 2014; 49: 343-8.

34. Charles G. Bud World Cup sponsorship drinks AB InBev sales growth. Campaign 2011. Available at: http://www.campaignlive. co.uk/article/1058217/bud-world-cup-sponsorship-drives-abinbev-sales-growth?src_site=marketingmagazine $\quad$ (accessed 30 June 2016) (Archived at http://www.webcitation.org/ 6iebRBoDp on 30 June 2016).

35. Foottit L. World Cup to boost pubs' business. Morning Advertiser 2009. Available at: http://www.morningadvertiser.co.uk/ Operators/Other-operators/World-Cup-to-boost-pubs-business (accessed 16 February 2016) (Archived at http://www. webcitation.org/6iebUN4m2 on 30 June 2016).

36. Babor T., Caetano R., Casswell S., Edwards G., Giesbrecht N., Graham K. et al. Alcohol: No ordinary Commodity, 2nd edn. New York: Oxford University Press; 2010.

37. Kantar Media. 2014 FIFA World Cup Brazil Television audience report. London, UK: Kantar Media; 2015. Available at: http://resources.fifa.com/mm/document/affederation/tv/ 02/74/55/57/2014fwcbraziltvaudiencereport $\% 28$ draft5\% 29\%28issuedate14.12.15\%29_neutral.pdf (accessed 16 February 2016) (Archived at http://www.webcitation.org/ 6iebWmd9g on 30 June 2016).

\section{Supporting Information}

Additional Supporting Information may be found in the online version of this article at the publisher's web-site:

Table S1 Ad characteristics.

Table S2 In-Game and Out-of-Game alcohol brand appearances by policy restrictiveness.

Table S3 In-Game and Out-of-Game alcohol brand appearances by match. 